\title{
More Promotions, More Sales? A Promotional Extent Optimization Model to Beauty Business
}

\author{
Nivaldo Kassouf Pizzinatto ${ }^{1}$, Nadia Kassouf Pizzinatto ${ }^{1} \&$ Andrea Kassouf Pizzinatto $^{1}$ \\ ${ }^{1}$ Master and Doctorate Business Program, Unimep- Universidade Metodista de Piracicaba, Brazil \\ Correspondence: Nadia Kassouf Pizzinatto, Master and Doctorate Business Program, Unimep- Universidade \\ Metodista de Piracicaba, Brazil. E-mail: nkp@nadiamarketing.com.br
}

Received: August 20, 2012 Accepted: September 3, 2012 Online Published: November 24, 2014

doi:10.5539/par.v4n1p1 URL: http://dx.doi.org/10.5539/par.v4n1p1

\begin{abstract}
This study contributes for marketing theory for analyzes the effect of Promotional extent (weighted percentage of a beauty's company's portfolio which is promoted to amplify sales by sales leverage) and whether it is possible to determine optimal Promotional extent. Multiple regressions were used to determine the effect of Promotional extent on leverage. The analysis was based on 2005-2007 data from both sales and margin from a cosmetics direct sales company. Using the regression equation found, a model was built to analyze and propose optimal Promotional extent. The results suggest that on the data analyzed, promotional leverage is negatively correlated with Promotional extent. Results also suggest that sometimes promoting more products can actually reduce sales, due to reduced promotional leverage. The model can be used as a managerial tool to determine optimal promotional policies.
\end{abstract}

Keywords: promotional investment, sales promotions, promotional extent model

\section{Introduction}

Sales promotions (such as price cuts, buy one-get-one-free) are important parts of most companies' marketing mix (Simpson, 2006: p.223; Gianfagna, 2013), specially to beauty business, which use using direct sales, the catalog, to sell their product. Direct sales depends also on consumer trustworthiness for the success of the business (Shareef et al., 2013). Promotional Sales Techniques and devices commonly used on a temporary basis, to make goods and services more attractive to final customers since it provides them some additional benefit or incentive (Rizvi et al., 2012, p. 2). The Promotional Marketing Association showed on a 2007 report that on average $34 \%$ of the marketing budget is allocated on sales promotions, compared to $23 \%$ on advertising and $7 \%$ on Public Relations (Kerin et al., 2007).

The purpose of sales promotion is to motivate the customers to immediately purchase a particular product thus enhancing the sales, but it is important the use of financial analysis and consumer survey, to analysis the impact of sales promotion (Rizvi et al., 2012). Kornfield et al. (2013) and Rosenthal (2002) showed that on some markets there is an upward trend on promotion. Over the counter medicines is an example mentioned by the author - the IMS Health and Competitive Media Reporting shows that Sales Promotions grew from 9\% of total marketing budget on 1996 to $16 \%$ on 2000 on this market. Lee (2013) pointed out that coupons contain a set of provisions that retailers to execute when consumers purchase the stipulated products or brands. In addition, they insisted that coupons should be understood as a way to stimulate sales by increasing purchase incentives. Thus, coupons serve as a stimulus for sales by offering discounted prices and additional or free benefits; they also increase consumer purchase motivation within a short period of time.

Given the growing use of promotions, which is common in business beauty management, the need to analyze and understand promotional variables became critical. Several papers, such as Kumar and Swaminathan (2005), Berger and Magliozzi (1992), Bray and Engelen (2007) focus on understanding variables that may affect promotional performance. The authors focused on price cuts, overall market share, and product size / volume. Kumar and Swaminathan (2005) analyzed the intensity of the promotional investment on Sales leverage. Coupons have been used by many consumers for more than a century and prior coupon research has indicated that coupons are effective in increasing short-term revenues across a wide range of countries (Lee, 2010). These coupons are frequently used in fidelity programs: special customers are gifted with additional discounts for chosen products. Traver and Rebstein (1982) analyzed coupons rebates, concluding that the discount and 
distribution intensity affect coupons' redeeming rate. Narasimhan, Scott and Sen (1996) focused the role of product's specific characteristics such as storage ease, relative price and others on promotional leverage. Sales promotion is one of the promotional mix including coupons, discounts, rebates, free samples, gifts and incentive items in order to observe an immediate effect on sales, since the customers have positive attitudes towards these (Megdadi \& Nusair, 2011: p.53). For Banerjee and Yancey (2010: p. 1) marketers should better understand customer demographic profiles to be able to identify their lifestyle - convenient timings, needs, and cravings, so that coupons can be accordingly designed. Mark et al. (2013, p: 1) believe that despite industry coupon redemption good rates, it is important to investigate how do retailers determine if a promotion is relevant to a consumer or what are the most effective segmentation approaches to guide the creation of targeted promotions.

One implicit variable on the promotional effort is the extension of a company's portfolio that should be promoted in order to leverage sales. For this study's sake, this variable will be called Promotional extent, and is defined as the weighted percentage of a company's portfolio that is promoted on a given time.

It is reasonable to suppose that a policy of promoting more or less the portfolio could affect overall sales, and from this assumption the hypothesis that there is an optimal level was derived. If this hypothesis is true, it would be possible to optimize the results and costs of promotional. In terms of originality, this study adds Promotional extent as a promotional variable to be considered on a company's promotional planning and optimization.

The analysis was based on a brazilian CFT (Cosmetics, Fragrances and Toiletries), company, using sales data of two years. Nevertheless, the method can be replicated for any company with stock keeping unit (SKU)-level data (Broeckelmann, 1999; Hudock, 2008 ; Wild, 2002).

\subsection{Study Hypothesis}

Given the study's scope and goals, the following hypothesis were defined.

If the higher the promotional extent, the higher should be the Sales - but with relative lower leverage. In other words, given an "A" scenario where only one product is promoted, and a "B" scenario where a second comparable product is promoted, on the " $\mathrm{B}$ " scenario the overall sales should be higher, but overall sales on " $\mathrm{B}$ " will not be twice as "A". So hypothesis H1 is proposed:

\section{H1 - Promotional extent affects promotional leverage.}

The hypothesis is based on the diminishing returns Law, firstly discussed by Anne Robert Jaques Turgot and later by Thomas Malthus. This law defines that in a given system, factor resource addition will lead to increasing returns until a given point, and from this point on returns will decrease (CASE; FAIR, 1999). In the same way, if one has 1000 SKUs (Stock Keeping Unit).

on portfolio and promote 10, it is reasonable to suppose that the promotional leverage effect will be different from promoting 700 out of 1000 SKUs (Stock Keeping Unit).

One analogous effect - even though based on intensity of distribution and not on promotional extent - was found by Rebstein and Traver (1982: p.103). Coupon redeeming rate was affect by the distribution intensity. The rate lowers as more and more coupons are distributed.

The hypothesis will be verified using multiple regression. The dependent variable will be Promotional Leverage, and the independent variables are Promotional extent and Promotional Expenditure (since it is different to promote a product with a $10 \%$ price cut or a $40 \%$ price cut). The hypothesis will be considered true if the $\beta$ coefficient for Promotional extent is negative, and significant with $p<0.05$.

Let $\mathrm{H} 1$ be true: Promotional Leverage diminishes when more products are promoted. Given that promotional sales by definition have lower profitability than regular sales of the same product, there should be a point where the company will lose nominal contribution margin by promoting more products. The hypothesis was tested using the regression equation found on $\mathrm{H} 1$ and through sensitivity analysis to find whether for a given promotional expenditure, there is an optimal Promotional extent level for contribution margin. Given the explanation above, the hypothesis $\mathrm{H} 2$ is:

\section{H2 - There is an optimal Promotional extent level.}

\section{Theoretical Background}

\subsection{Promotions and Sales Leverage}

Marketers continue to struggle to design effective and profitable promotional campaigns, which are common forms of promotion including coupons, seasonal price discounts, sweepstakes, contests, free samples, trial packages, loyalty reward programs, and free gifts. Promotions vary on multiple dimensions in an attempt to stand 
out and entice consumers to make a purchase (Laran \& Tsiros, 2013). Kerin et al (2007: p. 500) also state that "sales promotions are sales tools used to support to advertising and personal sales". Laran and Tsiros (2013) observes that the largest industry to adopt such a promotion is cosmetics, with $60 \%$ of department store makeup and $40 \%$ of prestige fragrance sales associated with such offers.

From a customer dynamics perspective, most customers migrate from a less valuable state (lower purchase incidence, fewer orders) to a more valuable state (higher purchase incidence, more orders) over time. Each segment reacts differentially to marketing activities. Retail promotions encourage purchase incidence customers, whereas catalogs influence purchase incidence and number of orders. Retail promotions have the strongest effect, significantly influencing the number of orders. The Active segment responds well to both catalogs and retail promotions. Catalogs, for example, serve as a trigger for members of the segment who tend to make purchases in response to catalog promotions (Mark et al., 2013).

These actions are meant to leverage baseline sales. Baseline sales are sales that would occur naturally, without any promotional intervention (Caniato et al., 2004).

\subsection{Promotional Leverage}

Following the topics regarding promotional leverage.

Promotional leverage can be defined as the increase of Sales due to a promotional effort, taking in account the regular sales of a product. (Narasimhan \& Neslin, 1996: p.18), mathematically:

\section{$\frac{\text { Promotional Sale }}{\text { Baseline Sales }}-1$}

It represents the additional sales given a non -promotional baseline. One question that arises is how to calculate the non-promotional, baseline sales. Caniato et al. (2004) suggest taking a time series of sales and eliminating peaks caused by promotional actions. After one cleans up the time series, the non-promotional baseline may be captured by moving averages or exponential smoothing.

\subsection{Promotional Leverage and Total Demand}

When a customer is faced with a promotion, usually sales rise. One important question is whether promotions can amplify total demand. Customers can buy more because they did not bought from another company, customers can buy more of the promoted product and not buy other non-promoted products, or customers can pile up "inventory". It can be consider that total market share, for instance, is a restrictive variable for coupons returns. When a product has high market share, probably returns will occur, but with lower promotional leverage. This happens because part of the sales would occur anyway, given the high market-share.

Davis (2005) found evidence of an increase in sales and profits when the product is promoted, but noticed that total market demand not necessarily increase.

Narasimhan, Scott and Sen (1996) noticed that products that can be easily stored and are non-perishable may leverage more when promotioned. This may happen because customers simply anticipate the demand and create "inventory".

These findings relate with marginal utility, diminishing returns, and total money availability (share of pocket) as related by Case and Fair (1999). It is not the scope of this study to deepen economical theory. But knowing that promotional efforts are affected by these economical principles, one can analyze how to optimize promotional sales.

\subsection{Promotional Extent and Sales Leverage}

When analyzing promotional performance, one question that arises is whether marginal efforts will lead to marginal gains. Kumar and Swaminathan (2005) mention that a higher promotional often leads to higher promotional leverage. For instance, a 30\% discount tends to generate more leverage than a $10 \%$ discount. Hence, promotional sales may come from promotional extent (more products promoted) or promotional leverage (higher promotional effort on fewer products). This mechanism can be seen on Figure 1. Assuming a) constant elasticity, b) equal baselines sales, and c) constant cannibalization, one can sell the same number of products by promoting one product with $40 \%$ discount, or promoting 4 with $10 \%$. This can be figured out by the gray area resulting from leverage and baseline sales, which is equal on both sides of the picture.

Both strategies are two-edge swords. For instance, a higher discount provokes more leverage, but with higher costs. A low discount, low leverage strategy on a high-sales product - an extent strategy - has by definition a high "sunk-cost". A lot of people that would buy anyway get a discount. 


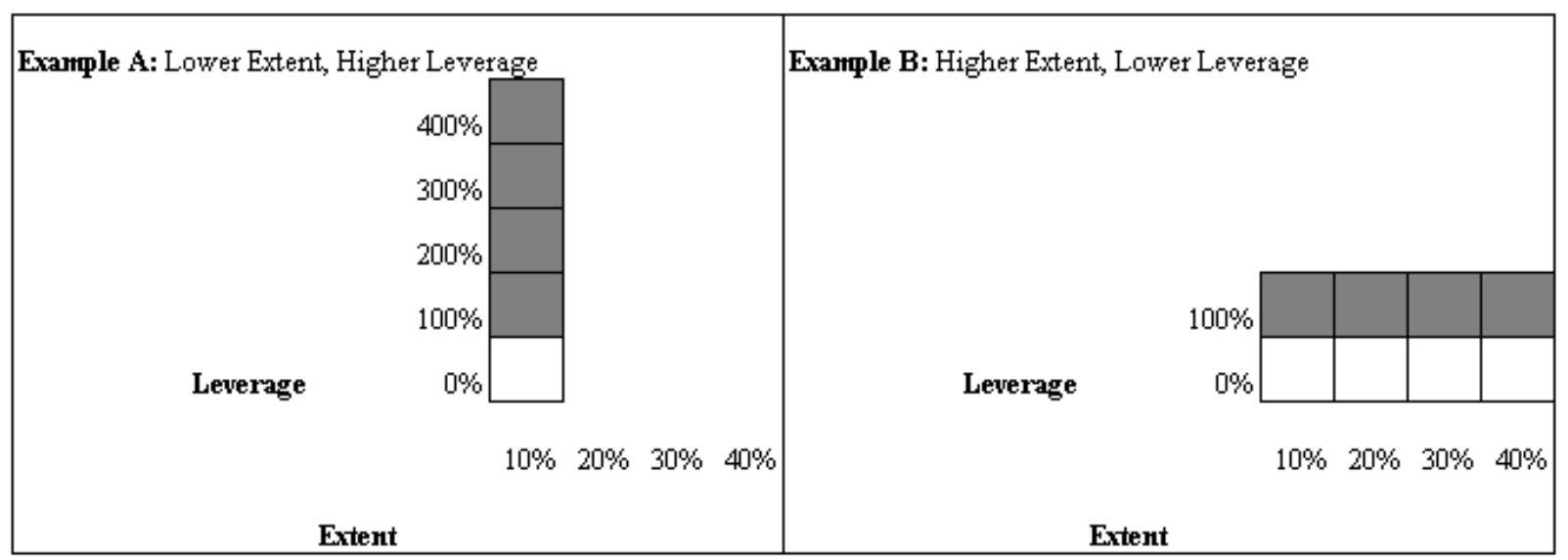

Notes:

Leverage $=$ Promotional Sales $/$ Baseline Sales -1

Extent $=$ weighted percentage of a company's portafolio that is promoted.

Figure 1. Leverage and extent: two ways of building promotional sales

Source: developed by the authors, based on data from the company under study.

\subsubsection{Time Series Seasonality and Causal Relationship Identification}

On properly analyzing sales leverage, one important factor to be considered is seasonality. Seasonality is periodic repetition of certain behavior on a time series, and is frequently found on social and natural processes (Nist \& Sematech, 2004).

Seasonality can be detected by visual inspection and auto correlation, lagging " $n$ " periods. For instance, a monthly series of data with seasonality will present auto correlation peaks on lag=12 (Moineddin, 2003).

It is important to try to eliminate seasonality when analyzing sales promotions and sales results. There are several methodologies that aim to eliminate this effect. Centered moving averages- used on Census II methods- and Differentiation - used on Box-Jenkins models - are good examples (Makridakis et al., 1997).

To verify the effect of promotional extent on leverage and promotional results, the following methodological procedures were used.

\subsubsection{Data Characteristics and Treatment}

The proposed method was applied on a brazilian, direct sales, cosmetics company. The company works with several product categories, and has the policy of offering at least one promotion per category on each catalog. This softens the issue of different category leverages and performances proposed by Narasimhan, Scott and Sen (1996), since each catalog data comprises every category. Each promotional catalog is a point on the time series, and there are 17 promotional catalogs every year. Figures are represented on brazilian reais (currency), except when mentioned.

Data used is secundary, obtained from existing databases on the studied company and collected by availability. No random sampling was used to obtain the data.

\subsubsection{Baseline Estimate}

To calculate leverage, it is necessary to know how much the product would sell without the promotion - the baseline sales. To estimate the baseline, the procedure proposed by Caniato et al. (2004) was used. This procedure recommends excluding promotional peaks from the time series and posterior smoothing by centered moving averages. The example on Figure 2 shows how peaks are substituted by interpolations and how the methodology handles the trend element. 


\section{Total Sales (with Promotions) $\mathrm{x}$ Baseline Estimate}

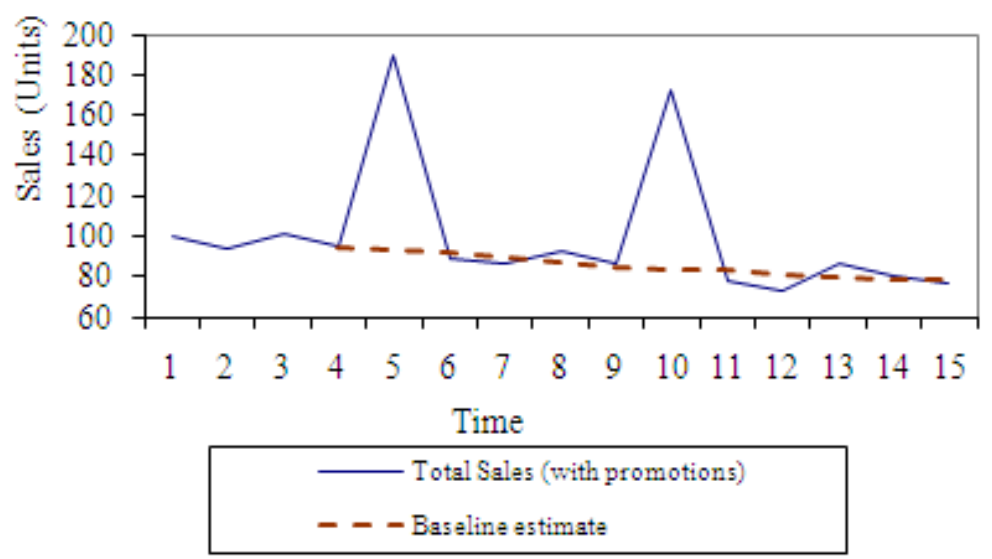

Figure 2. Total sales and baseline estimates

Source: adapted from Caniato et al (2004).

\subsection{Calculating Promotional Extent and Leverage}

With all the baseline estimates, one can calculate the weighted percentage of the portfolio that was promoted on each catalog. For the purpose of these study, this percentage will be called promotional extent. The calculus is given by the sum of the baselines of all promoted products, divided by the sum of all baselines of all products (promoted or not). Figure 3 will provides an step by step explanation. Following, the table with promotional extent and real sales leverage of products on promotional.

Table 1. Calculating promotional extent and real sales leverage of products on promotion

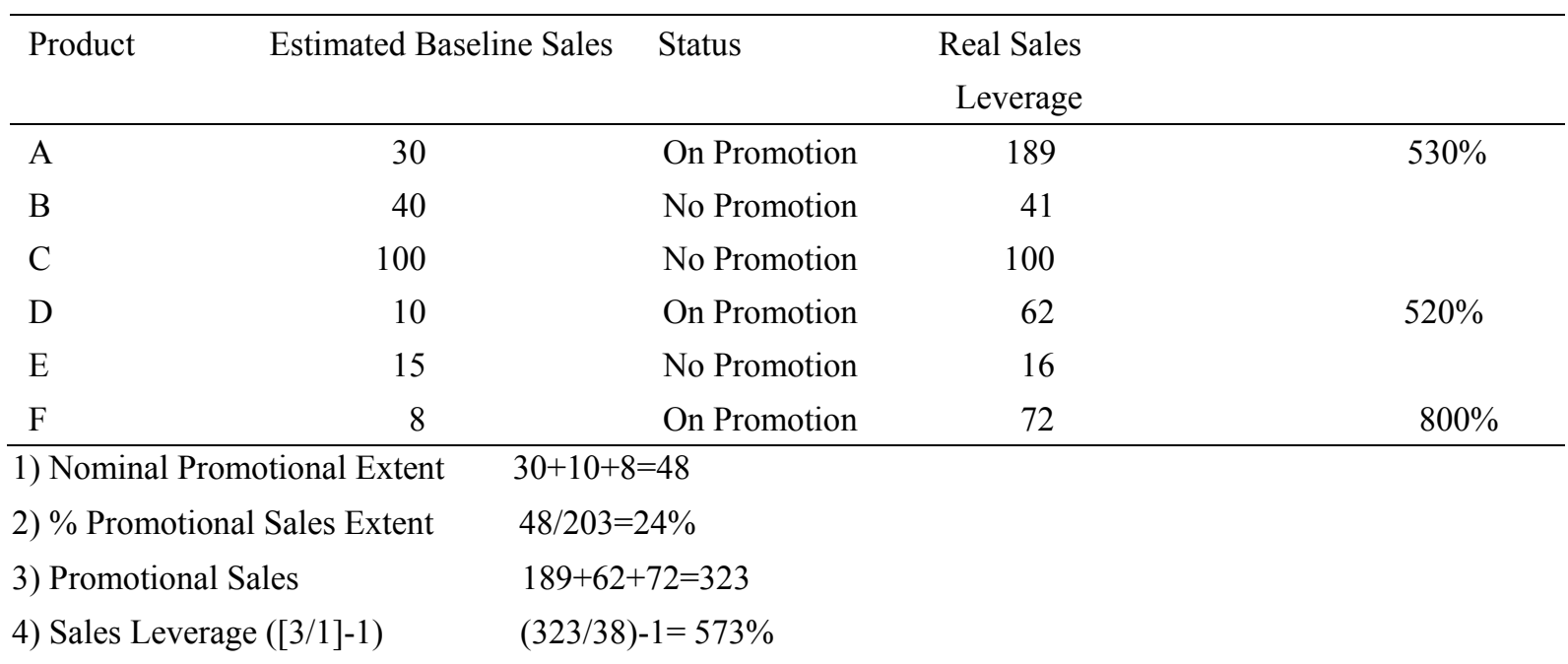

Source: developed by the authors, based on data from the company under study.

To calculate promotional leverage, the sales of all promoted products on a given catalog were added up, and this sum was divided by the sum of the baseline of these promoted products. From the resulting number, a -1 adjustment is needed to isolate the effect of the baseline sales and represent only sales generated by promotions. Hence, when one says that leverage is $400 \%$, it means that promotions added sales equivalent to $4 \mathrm{x}$ the baseline sales.

\section{a) Promotional expedinture and leverage}

Kumar and Swaminathan (2005) mention the intensity of promotional expenditure as leverage driver. To isolate 
this effect from promotional extent, the promotional expenditure, measured as perceived discount divided by total sales, was measured. To preserve confidentiality, values were divided by a given factor, what does not change correlation or regression analysis (Martins, 2011).

\section{b) Verifying and isolating seasonality}

Seasonality was verified on the time series by auto-correlation on total sales, as proposed by Moineddin (2003: p.2). Given that annual seasonality was present with $p<0.05$, data were aggregate on yearly level. Hence, one can identify yearly leverage, promotional extent, and promotional expenditure. From this first aggregate, a yearly moving average was generated to smooth seasonality. This allows a better understanding of the effect of promotional extent and promotional expenditure on leverage. This procedure was based on the Census II method (Makridakis et al., 1997).

\section{c) Regression Analysis}

From the moving average time series, a multiple regression analysis was performed. A simple regression option was discarded since a co-variation of promotional expenditure and promotional extent could lead to erroneous conclusions.

The independent variables were promotional expenditure and promotional extent, and the dependent variable was promotional leverage. The regression was verified using the $\mathrm{F}$ test, and the $t$ values of $\beta$ on Promotional extent and Leverage. The $p$ value used to accept or reject the overall regression and the individual predictors was 0.05 .

\section{d) Optimizing the scenario}

The main managerial goal of the study is to help to determine optimal promotional policies. Thus, from the multiple regression equation previously identified, several scenarios were generated. Holding promotional expenditure constant and changing promotional extent, different leverage scenarios were generated. The leverage output and the promotional extent inputs were combined to calculate total sales using the following model:

\section{Total Sales $=$ Non Promotional Sales + Promotional Sales}

Non Promotional Sales = Total Baseline sales x (1-Promotional extent \%)

Promotional Sales $=$ [Total Baseline sales $x$ Promotional extent\% $x(1+$ Promotional Leverage $)]$

Total Sales $=$ Total Baseline sales $x(1-$ Promotional extent \%) $+[$ Total Baseline sales $x$ Promotional extent $\% x$ $(1+$ Promotional Leverage)]

The logic on non-promotional sales is: if the sum of all estimated baselines is 100 , but $20 \%$ will be put on promotions, the non-promotional sales should be $100 \times(1-20 \%)=80$.

On the promotional side, the logic is: if from an overall portfolio that would sell 100 without promotions, $20 \%$ was promoted with a $300 \%$ leverage, the promotional sales should be $100 \times 20 \% \times(1+300 \%)=80$. Figure 3 visually shows the underlying logic and calculations of the model.

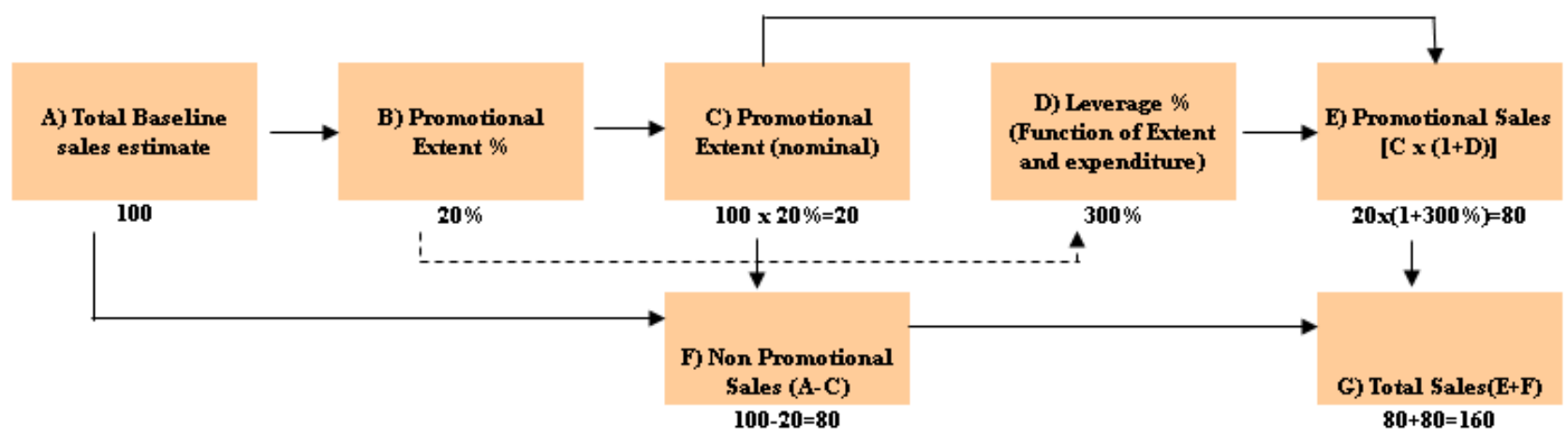

Figure 3. The total sales model

Source: developed by the authors, based on data from the company under study.

Running several scenarios with fixed promotional expenditure and variable promotional extent, the optimal point for total sales and margin were determined as a function of promotional extent. 


\section{Results and Discussion}

From the methodological procedures previously discussed, the following results were obtained.

The moving average procedure used to isolate seasonality resulted on the data on Figure 4. Columns D and E, together with promotional expenditure data, were used on regression analysis. The results of the regression analysis can be found on Figure 4.

\begin{tabular}{|c|c|c|c|c|c|c|c|c|c|}
\hline $\begin{array}{l}\text { Catalog ( } 1 \text { year } \\
=17 \text { catalogs })\end{array}$ & Promotional Sale & $\begin{array}{c}\text { Total Baseline } \\
\text { Sales }\end{array}$ & $\begin{array}{c}\text { Non-Promotional } \\
\text { Sales }\end{array}$ & $\begin{array}{c}\text { Nominal } \\
\text { Promotional } \\
\text { Extent } \\
\end{array}$ & & & & & \\
\hline 1 & 60.270 & 80.343 & 87.841 & 14.733 & & & & & \\
\hline 2 & 64.436 & 88.093 & 96.009 & 12.221 & & & & & \\
\hline 3 & 98.914 & 84.948 & $98.355 \Gamma$ & $\overline{18.526}$ & & & & & \\
\hline 4 & 86.086 & 125.565 & 92.9381 & 12.5001 & & & & & \\
\hline 5 & 110.083 & 80.934 & 100.256 & 19.840 & & & & & \\
\hline 6 & 80.016 & 85.120 & 97.993 & 16.538 & & & & & \\
\hline 7 & 116.433 & 85.649 & $98.657 \mathrm{i}$ & 21.381 & & & & & \\
\hline 8 & 71.894 & 88.531 & 93.698 & 17.891 & & & & & \\
\hline 9 & 95.394 & 89.930 & $91.920 \mathrm{i}$ & 13.952 & & & & & \\
\hline 10 & 100.840 & 85.290 & 99.216 & 16.071 & & & & & \\
\hline 11 & 122.147 & 85.625 & 100.047 & 21.830 & & & & & \\
\hline 12 & 113.150 & 96.338 & 101.623 & 15.000 & & & & & \\
\hline 13 & 108.947 & 96.415 & 98.533 & 18.291 & & & & & \\
\hline 14 & 112.965 & 90.912 & 101.875 & 17.340 & & & & & \\
\hline 15 & 129.436 & 86.985 & 104.350 & 19.922 & & & & & \\
\hline 16 & 77.303 & 103.501 & | & 21.541 & $\begin{array}{l}\text { A) Promotional } \\
\text { Sales (Moving } \\
\text { Average, } 17 \\
\text { catalogs) }\end{array}$ & $\begin{array}{c}\text { B) Non } \\
\text { Promotional } \\
\text { Sales (Moving } \\
\text { Average, } 17 \\
\text { catalogs) }\end{array}$ & $\begin{array}{l}\text { C) Nominal } \\
\text { Extent (Moving } \\
\text { Average, } 17 \\
\text { catalogs) }\end{array}$ & $\begin{array}{l}\text { D) Leverage } \\
\text { ([A/C]-1) }\end{array}$ & $\begin{array}{c}\text { Promotional } \\
\text { Extent, \% (C/B) }\end{array}$ \\
\hline 17 & 122.000 & 91.635 & 99.990 & 22.222 & 1.670 .315 & 1.672 .423 & 299.797 & $457,1 \%$ & $17,9 \%$ \\
\hline 18 & 101.114 & 66.861 & 86.334 & 13.554 & $1.711 .159^{\circ}$ & $1.670 .916^{\prime \prime}$ & 298.618 & $473,0 \%$ & $17,9 \%$ \\
\hline 19 & 89.040 & 80.058 & 91.351 【 & 12.280 & 1.735 .763 & $1.666 .258^{\boldsymbol{T}}$ & 298.676 & $481,2 \%$ & $17,9 \%$ \\
\hline 20 & 123.447 & 88.713 & $102.165^{2}$ & $\overline{18} \cdot \overline{644}$ & 1.760 .295 & $1.670 .067^{\$}$ & $\overline{2} 98.795$ & $489,1 \%$ & $17,9 \%$ \\
\hline 21 & 123.042 & 117.037 & 96.350 & $12.907^{\prime}$ & $1.797 .252^{\prime}$ & $1.673 .479^{\prime \prime}$ & 299.202 & $500,7 \%$ & $17,9 \%$ \\
\hline 22 & 140.843 & 80.447 & 93.719 & $14.416^{\prime}$ & $1.828 .012^{\nabla}$ & $1.666 .941^{\mathrm{V}}$ & 293.778 & $522,2 \%$ & $17,6 \%$ \\
\hline 23 & 81.397 & 89.036 & 93.945 & $11.617^{\prime}$ & $1.829 .393^{\mathrm{V}}$ & $1.662 .894^{\mathrm{V}}$ & 288.858 & $533,3 \%$ & $17,4 \%$ \\
\hline 24 & 120.485 & 96.769 & 98.268 & $15.092^{\prime}$ & $1.833 .445^{\prime}$ & $1.662 .504^{\prime \prime}$ & 282.569 & $548,8 \%$ & $17,0 \%$ \\
\hline 25 & 80.944 & 91.908 & 97.191 & $11.057^{\prime}$ & $1.842 .495^{\prime}$ & $1.665 .997^{\prime \prime}$ & 275.735 & $568,2 \%$ & $16,6 \%$ \\
\hline 26 & 122.731 & 86.046 & 100.156 & $13.402^{\prime}$ & $1.869 .831^{\prime}$ & $1.674 .234^{\prime}$ & 275.186 & $579,5 \%$ & $16,4 \%$ \\
\hline 27 & 103.026 & 84.886 & 95.630 & $11.128^{\prime}$ & $1.872 .017^{\prime}$ & $1.670 .648^{\prime \prime}$ & 270.242 & $592,7 \%$ & $16,2 \%$ \\
\hline 28 & 105.907 & 84.485 & 108.141 & $15.006^{\prime}$ & $1.855 .777^{\prime}$ & $1.678 .743^{\prime}$ & 263.418 & $604,5 \%$ & $15,7 \%$ \\
\hline 29 & 120.818 & 134.432 & 115.037 & $21.598^{\prime \prime}$ & $1.863 .445^{\prime}$ & $1.692 .157^{\prime \prime}$ & 270.016 & $590,1 \%$ & $16,0 \%$ \\
\hline 30 & 137.182 & 107.206 & 116.682 & $16.802^{\prime}$ & $1.891 .680^{\prime}$ & $1.710 .306^{\mathrm{V}}$ & 268.527 & $604,5 \%$ & $15,7 \%$ \\
\hline 31 & 138.381 & 101.089 & 110.181 & $19.712^{\prime}$ & $1.917 .095^{\prime}$ & $1.718 .612^{\prime}$ & 270.900 & $607,7 \%$ & $15,8 \%$ \\
\hline 32 & 155.907 & 96.801 & 107.866 & $14.757^{\prime}$ & $1.943 .566^{\prime \prime}$ & $1.722 .128^{\prime \prime}$ & 265.735 & $631,4 \%$ & $15,4 \%$ \\
\hline 33 & 104.521 & 116.548 & 120.244 & $15.563^{\prime}$ & $1.970 .784^{\prime}$ & $1.733 .250^{\circ}$ & 259.757 & $658,7 \%$ & $15,0 \%$ \\
\hline 34 & 122.000 & 91.635 & 99.990 & $22.222^{\prime}$ & $1.970 .784^{\vee}$ & $1.733 .250^{\mathrm{V}}$ & 259.757 & $658,7 \%$ & $15,0 \%$ \\
\hline
\end{tabular}

Figure 4. Original time series and moving average time series

Source: elaborated by the authors, based on the original data from the company under study.

\subsection{The Promotional Extent, Promotional Expenditure and Leverage Relationship}

With promotional extent and promotional expenditure as independent variables and leverage as the dependent variable, the results on Figure 5 were obtained. Multiple regression analysis shows and adjusted $\mathrm{R}^{2}=0,93$. With $p<0,05$, the overall regression is accepted, with $F=113,25$. The slope for promotional extent is negative, and its $t$ value is -3.63 , which allows $\mathrm{H} 1$ to be accepted with $p<0,05$. This means that there are diminishing returns on the promotional extent, since adding more products on promotions leads to less leverage.

It is relevant to mention that results suggests that promotional expenditure tends to elevate leverage, as stated by Kumar and Swaminathan (2005) - the slope for promotional expenditure is positive and relevant with $p<0,05$. 


\begin{tabular}{lr}
\multicolumn{2}{c}{ Regession Results } \\
\hline R multipilo & 0,970 \\
R-Square & 0,942 \\
Adjusted R-Square & 0,933 \\
Statidard Ertor & 0,147 \\
$n$ & 17 \\
\hline
\end{tabular}

\begin{tabular}{|c|c|c|c|c|}
\hline & $g !$ & $5 Q$ & $M Q$ & $F$ \\
\hline Regression & 2 & 4,865 & 2,433 & 113,256 \\
\hline Residuals & 14 & 0,301 & 0,021 & \\
\hline Total & 16 & 5,166 & & \\
\hline & Coeficient & Std Error & Stat t & P-value \\
\hline Intereept & 6,926 & 3,393 & 2,041 & 0,061 \\
\hline Ptomotional Expenditute & 73,856 & 32,754 & 2,255 & 0,041 \\
\hline Ptomotional Extent & $(33,705)$ & 9,269 & $(3,636)$ & 0,003 \\
\hline
\end{tabular}

Figure 5. Regression results: leverage as a function of promotiona extent and promotional expenditure Source: elaborated by the authors, based on data on Figure 5 plus Promotional Expenditure data.

\subsection{Optimizing Promotional Extent}

Given that adding promotional extent diminishes Leverage, and given the fact the promoted products usually sell with lower margins, to identify optimal promotional extent level is desirable. Using the regression equation on Figure 4 and using the Total Sales model proposed on Table 1, several scenarios were run to try to determine an optimal policy for promotional extent. Fixing the promotional expenditure on the levels proposed by company's top management and varying promotional extent, the results on Figure 6 were obtained.

Results suggest that the optimal promotional extent is around $13 \%$, which helps to determine policies and guidelines for promotional planning. Further promotional extent seems to only reduce non-promotional sales on a higher rate than it generates promotional sales. This is caused by the diminishing leverage - and consequent diminishing growth of Promotional Sales- caused by additional Promotional extent, which can be visually understood on Figure 7.

\begin{tabular}{|c|c|c|c|c|c|c|c|c|}
\hline $\begin{array}{c}\text { A) Total Baseline } \\
\text { Sales }\end{array}$ & $\begin{array}{c}\text { B) } \\
\text { Promotional } \\
\text { Extent } \%\end{array}$ & $\begin{array}{l}\text { C) Nominal } \\
\text { Extent (Ax } \\
\text { B) }\end{array}$ & $\begin{array}{c}\text { D) Leverage } \% \\
(6,9+73,8 \times \text { Prom } \\
\text { Exp }-33,7 \times \text { Prom } \\
\text { Extent } \%) \\
\end{array}$ & $\begin{array}{c}\text { E) } \\
\text { Promotional } \\
\text { Sales [C x } \\
\text { (1+D)] }\end{array}$ & $\begin{array}{l}\text { F) Non- } \\
\text { Promotional } \\
\text { Sales (A-C) } \\
\text { R } \$ 000\end{array}$ & $\begin{array}{l}\text { G) Total Sales } \\
\text { (E+F)em R\$ } \\
000\end{array}$ & $\begin{array}{c}\text { H) Gross } \\
\text { Margin R\$ } \\
000\end{array}$ & $\begin{array}{l}\text { D) Marginal } \\
\text { Revenue (E- } \\
\text { C) } \mathrm{R} \$ 000\end{array}$ \\
\hline 115.928 & $2 \%$ & 2.319 & $1336 \%$ & 33.292 & 113.610 & 146.902 & 63.886 & 30.973 \\
\hline 115.928 & $4 \%$ & 4.637 & $1230 \%$ & 61.684 & 111.291 & 172.976 & 72.238 & 57.047 \\
\hline 115.928 & $6 \%$ & 6.956 & $1125 \%$ & 85.177 & 108.973 & 194.150 & 78.963 & 78.221 \\
\hline 115.928 & $8 \%$ & 9.274 & $1019 \%$ & 103.770 & 106.654 & 210.424 & 84.061 & 94.496 \\
\hline 115.928 & $10 \%$ & 11.593 & $913 \%$ & 117.463 & 104.336 & 221.799 & 87.531 & 105.870 \\
\hline 115.928 & $12 \%$ & 13.911 & $808 \%$ & 126.257 & 102.017 & 228.274 & 89.373 & 112.345 \\
\hline 115.928 & $13,3 \%$ & 15.418 & $739 \%$ & 129.345 & 100.510 & 229.855 & 89.698 & 113926 \\
\hline 115.928 & $15 \%$ & 17.737 & $633 \%$ & 130.054 & 98.191 & 228.245 & 88.855 & 112.317 \\
\hline 115.928 & $17 \%$ & 20.056 & $528 \%$ & 125.863 & 95.873 & 221.736 & 86.385 & 105.807 \\
\hline 115.928 & $19 \%$ & 22.374 & $422 \%$ & 116.773 & 93.554 & 210.327 & 82.288 & 94.398 \\
\hline 115.928 & $21 \%$ & 24.693 & $316 \%$ & 102.783 & 91.236 & 194.018 & 76.563 & 78.090 \\
\hline 115.928 & $23 \%$ & 27.011 & $211 \%$ & 83.893 & 88.917 & 172.810 & 69.211 & 56.881 \\
\hline
\end{tabular}

Figure 6. Several scenarios for promotional extent

Source: elaborated by the authors, based on regression equation on Figure 6 plus Total Sales model proposed on Figure 4.

The Figure 7 reports the effect of additional Promotional extent on Total Sales and Margins. 


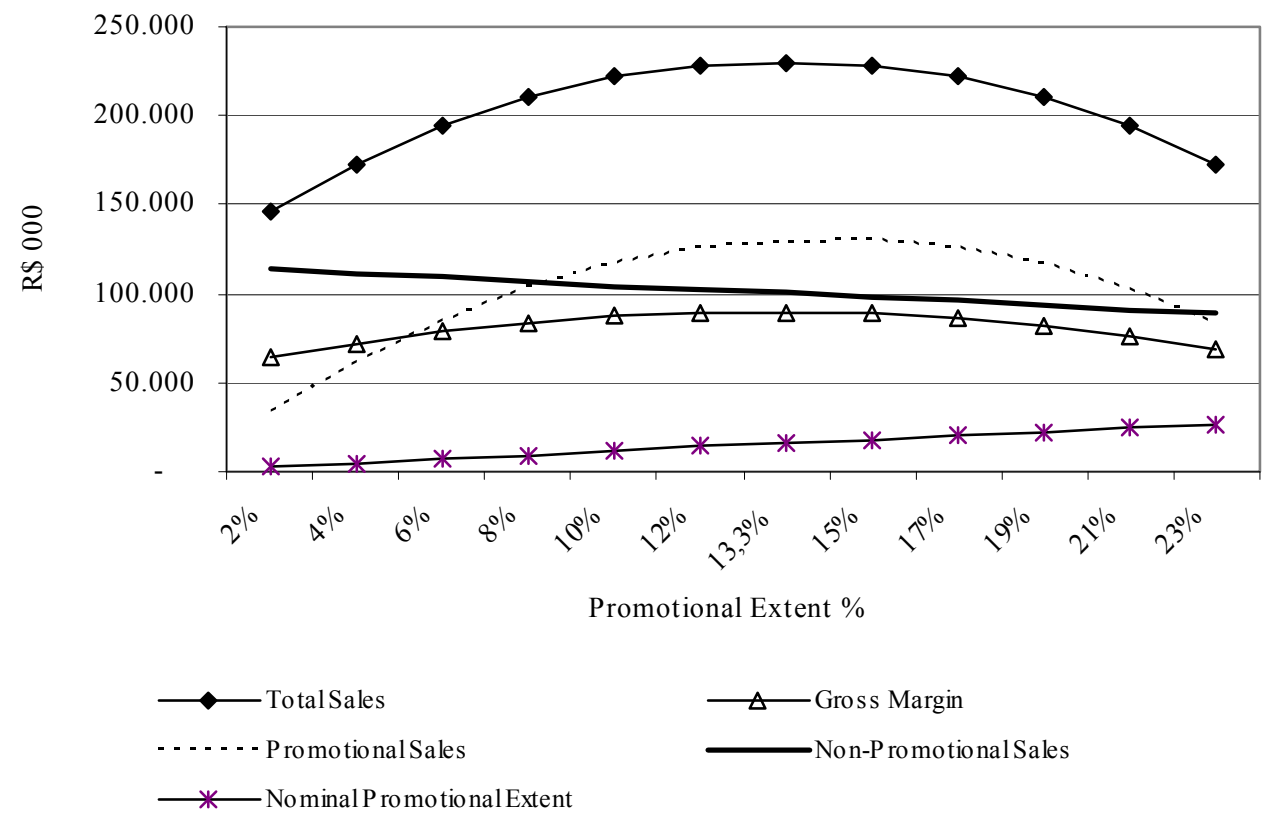

Figure 7. The effect of additional promotional extent on total sales and margins

Source: Elaborated based on data on Figure 6.

\subsection{Study Limitations and Opportunities for Further Research}

The study was conducted on an aggregate level to determine optimal levels. Some product categories may show different patterns. Hence the conclusions are valid only on the aggregate level but do not automatically apply for the category level. A category level analysis is an opportunity for further research. For instance, an optimal policy for a company level Promotional extent may be $16 \%$, but this may change depending on the categories. Face care products may have a different slope for promotional extent than shampoos, and so on.

It is also important to say that data availability was limited, and hence the regression analysis may suffer from over fitting. While this probably won't change the overall conclusion, it is important to mention this caveat on $\mathrm{R}^{2}$ and another regression matters $-\mathrm{R}^{2}$ may be overestimated.

Finally, the conclusion applies for this given company. Thus, while the methodology and overall hypothesis may be valid, results will probably vary from company to company.

\section{Conclusions}

On the studied case, Promotional extent negatively affects Promotional Leverage. The managerial conclusion is that the use of promotions to grow Total Sales should be carefully done, because it can be marginally negative for the company. This may happen for several reasons:

a) one can be selling on promotional prices for customers that would buy anyway (once a $10 \%$ price cut is given, all customers that would buy anyway pay $10 \%$ less). This is a natural and expected "sunk cost" of promotional efforts that is usually counteracted by Promotional Leverage. Considering that Promotional extent may decrease Promotional Leverage and automatically increases the "sunk cost" of a promotion (since more products are promoted and affected by discounts), there may be a point where the promotion does not pay off.

b) customers may have a fixed budget for a given kind of expense (Cosmetics, for instance), and adding more products on promotion can only divide sales. This may explain the diminishing Promotional Leverage. Results suggest that is possible to determine an optimal Promotional extent level to generate policies for promotional planning, using the regression analysis and the Total Sales model proposed on Figure 3.

One important caveat is that this an analysis based on data of only a company. Hence, further research on other companies can verify whether this is a company-specific issue or an overall economical factor on promotional planning. 


\section{References}

Banerjee, S., \& Yancey, S. (2010). Enhancing mobile coupon redemption in fast food campaigns. Journal of Research in Interactive Marketing, 4(2), 97-110. http://dx.doi.org/10.1108/17505931011051650

Berger, P. D., \& Magliozzi, T. (1992). Optimal Co-operative Advertising Decisions in Direct-Mail Operations. The Journal of the Operational Research Society, 43(11), 1079-1087. http://dx.doi.org/10.1057/jors.1992.165

Bray, J. W., Loomis, B., \& Engelen, M. (2007). Correlates of In-Store Promotions for Beer: Differential Effects of Market and Product Characteristics. Journal of Studies on Alcohol and Drugs, 68(2), 220.

Broeckelmann, R. G. (1999). Inventory classification innovation: paving the way for electronic commerce and vendor managed inventory. Boca Raton, FL: St Lucie Press. Retrieved May 22, 2008, from http://books.google.com/books?id=kCJylW0ddxAC\&dql=pt-PT

Caniato, F. et al. (2004). Forecasting demand flutuations due to promotional activities: A case in the fresh food industry. In: $20^{\text {th }}$ POMS CONFERENCE, 2002, San Francisco.

Case, K. E., \& Fair, R. C. (1999). Principles of economics. Upper Saddle River: Prentice-Hall.

Davis, G. C. (2005). The significance and insignificance of demand analysis in evaluating promotion programs. $\begin{array}{llll}\text { American Journal of Agricultural Economics, } & \text { 87(3), 673-688. }\end{array}$ http://dx.doi.org/10.1111/j.1467-8276.2005.00755.x

Gianfagna, J. (2013). 13 ways to get lucky with an award. LifeHealthPro.

Hudock, B. (2008). Warehouse space and layout planning. In J. A. Tompkins, \& Jerry. D. Smith. (Eds.), The warehouse management handbook (2nd ed.). Raleigh, NC: Tompkins Press. Retrieved May 5, 2008, from http://books.google.com/books?id=oHkA15BCY9MC\&hl=pt-PT

Kerin, R., Berkowitz, E., Hartley, S., \& Rudelius, W. (2007). Marketing (6th ed.). São Paulo: Irwin-McGraw Hill.

Kornfield, R., Donohue, J., Berndt, E. R., \& Alexander, G. C. (2013, March). Promotion of Prescription Drugs to Consumers and Providers 2001-2010. Plos One.

Kumar, V., \& Swaminathan, S. (2005). The different faces of coupon Elasticity. Journal of Retailing, 81(1), 1-13. http://dx.doi.org/10.1016/j.jretai.2005.01.003

Laran, J., \& Tsiros, M. (2013). An Investigation of the Effectiveness of Uncertainty in Marketing Promotions involving Free Gifts. Journal of Marketing, 7. http://dx.doi.org/10.1509/jm.11.0255

Lee, H. S. (2010). Effects of the coupon expiration date and stamp on consumer's value perception of cupons. International Journal of Business and Management, 5(8). http://dx.doi.org/10.5539/ijbm.v5n8p13

Mark, T., Lemon, K., Vandenbosch, M., Bulla, J., \& Maruotti, A. (2013). Capturing the Evolution of CustomerFirm Relationships: How Customers Become More (or Less) Valuable Over Time. Journal of Relaiting, $89(3)$.

Martins, G. A. (2011). Estatística geral e aplicada. São Paulo.

Megdadi, Y. A., \& Nusair, T. T. (2011). Shopping Consumer Attitudes toward Mobile Marketing: A Case Study among Jordanian User's. International Journal of Marketing Studies, 3(2). http://dx.doi.org/10.5539/ijms.v3n2p53

Moineddin, R., Upshur, R. E. G., Crighton, E., \& Mamdani, M. (2003). Autoregression as means of assessing the strength of seasonality in a time series. Population Health Metrics, 10(1), 1-7.

Narasimhan, C., Neslin, S. A., \& Sen, S. K. (1996). Promotional elasticities and category characteristics. Journal of Marketing, 60(2), 17. http://dx.doi.org/10.2307/1251928

Reibstein, D. J., \& Traver, P. A. (1982).Factors Affecting Coupon Redemption Rates. Journal of Marketing, 46(4), 102. http://dx.doi.org/10.2307/1251366

Rizvi, S. N. Z., Malik, S., \& Zaidi, S. F. B. (2012). Short Term and Long Term Impact of Sales Promotion on Organizations' Profitability: A Comparative Study between Convenience and Shopping Goods. International Journal of Business and Management, 7(5).

Rosenthal, M. B., Berndt, E. R., Donohue, J. M., Frank, R. G., \& Epstein, A. M. (2002). Promotion of prescription drugs to Consumers. The New England Journal of Medicine, 346(7), 498-505. 
http://dx.doi.org/10.1056/NEJMsa012075

Shareef, M. A., Archer, N., Fong, W. F., Rahman, M. O., \& Mann, I. J. (2013). Online Buying Behavior and Perceived Trustworthiness. British Journal of Applied Science \& Technology, 3(4), 662-683. http://dx.doi.org/10.9734/BJAST/2013/2394

Simpson, L. (2006). Enhancing food promotion in the supermarket industry: A framework for sales promotion success. International Journal of Advertising, 25(2), 223-245.

Wild, T. (2002). Best practice in inventory management (2nd ed.). Oxford, RU: Butterworth-Heinemann. Retrieved May 20, 2008, from http://books.google.com/books?id=QseYtErYgBoC\&dq=pt-PT

Zoteri, G., Kalschmidt, M., \& Caniato, F. (2005). The impact of aggregation level on forecasting performance. International Journal of Production Economics, $479-491$. http://dx.doi.org/10.1016/j.ijpe.2004.06.044

\section{Copyrights}

Copyright for this article is retained by the author(s), with first publication rights granted to the journal.

This is an open-access article distributed under the terms and conditions of the Creative Commons Attribution license (http://creativecommons.org/licenses/by/3.0/). 